MODELING THE PACIFIC OCEAN

\title{
Marine Reserve Design [Video]
}

Douglas Steigerwald ${ }^{a}$

Keywords: economic and ecological equilibrium, marine reserve design

https://doi.org/10.1525/001c.22183

Marine sanctuaries are an important part of ocean conservation today, but because of their local economic effects on industries such as fisheries, gas and oil extraction, and tourism, they produce conflicts of interest between different stakeholders and value systems. These conflicting interests were on display in the proposal for new marine reserve boundaries for the Channel Islands Marine Sanctuary, which was first created in 1980 . To capture the interplay of these competing interests, a statistical decision maker model was built. The econometric model predicts the response of fishermen - in this case urchin divers - to each proposed marine preserve boundary. The predicted response could then be factored into the design of the preserve, to more accurately capture the actual biological gains from each proposed boundary.

Video available at: https://vimeo.com/527396635

a Professor Douglas Steigerwald received his B.A. from Pomona College and his PhD from UC Berkeley, where he studied efficiency bounds for semiparametric estimators. He immediately joined the faculty at UC Santa Barbara and is now also a Professor, by courtesy, of Statistics. At Santa Barbara he develops Econometric Methods to solve problems that arise at the intersection of Economics, Computer Science, Geography, and Environmental Science. Professor Steigerwald directed the American Economic Association's Summer Training Program, advised the Sloan Foundation on graduate research, and served as chair of the National Science Foundation's Graduate Research Fellowship Program in Economics. 


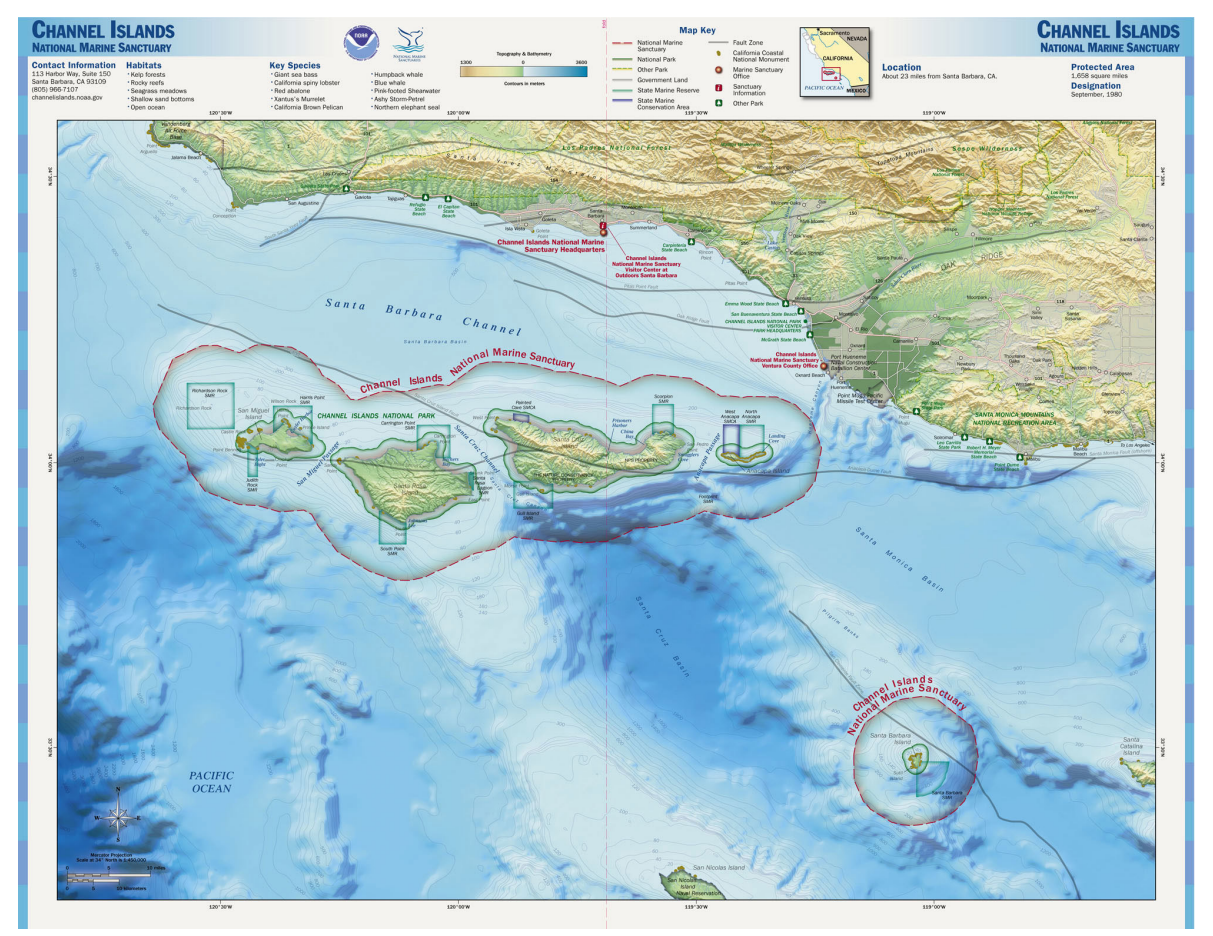

Figure 1: Channel Island Marine Sanctuary, Santa Barbara

Image courtesy of NOAA, National Sanctuary. 